\title{
Quiste de segundo arco branquial del espacio parafaríngeo en recién nacido: Reporte de un caso
}

\section{Second branchial cleft cyst parapharyngeal space in newborn: A case report}

\author{
Romina Ovalle A , Ana María Contador C'1, Rocco Calabrese G'1.
}

\begin{abstract}
RESUMEN
Dentro de los quistes cervicales congénitos los quistes branquiales son los segundos en frecuencia luego del quiste tirogloso, representando el $24 \%$ de los casos. De éstos, Ios quistes de segundo arco branquial son los más frecuentes con 90\%-95\% de los casos. Se presentan en un amplio rango de edad siendo comúnmente diagnosticados en niños mayores y adultos, cuya primera manifestación clínica puede ser un aumento de volumen relativamente brusco por infección. Se presenta el caso clínico de un recién nacido (RN) que debuta a las 48 horas de vida con estridor y dificultad para la alimentación oral. El estudio de imágenes con tomografía computarizada (TC) y resonancia magnética (RM) muestran una lesión quística del espacio parafaríngeo derecho que se proyecta hacia nasofaringe y orofaringe. Se realiza la exéresis de la lesión vía transoral. Biopsia rápida y diferida confirman diagnóstico de quiste branquial. Se revisa literatura sobre quistes de segundo arco branquial de ubicación en el espacio parafaríngeo siendo muy pocos los casos reportados.
\end{abstract}

Palabras clave: Quiste segundo arco branquial, espacio parafaríngeo, recién nacido.

\begin{abstract}
Within the congenital cervical necks, the branchial cleft cyst are the second in the frequency after the shooting, accounting for $24 \%$ of the cases. Of the Second branchial cleft cyst are with the most frequent with $90-95 \%$ of the cases. It occurs in a wide range of ages and is commonly diagnosed in older children and adults, whose first clinical manifestation may be an increase in volume after infection. We present a clinical case of newborn that debuts at 48 hours of life with stridor and difficulty for oral feeding. The imaging study with Computed Tomography (CT) and Magnetic Resonance imaging (MRI) show a cystic lesion of the right parapharyngeal space projecting into the nasopharynx and oropharynx. The excision of the transoral lesion is performed. Frozen biopsy and diagnostic biopsy demonstrating a branchial cyst. We review the literature on the second branchial cleft cyst of the location in the parapharyngeal space with very few reported cases.
\end{abstract}

Key words: Branchial cleft cyst, parapharyngeal space, newborn.

1 Médico Servicio Otorrinolaringología, Hospital Barros Luco Trudeau.

Recibido el 26 de febrero, 2017. Aceptado el 9 de abril, 2017. 


\section{INTRODUCCIÓN}

Dentro de los quistes cervicales congénitos los quistes del conducto tirogloso son los más frecuentes en el $75 \%$ de los casos. Le siguen en segundo lugar los quistes branquiales representando el $24 \%{ }^{1}$. Estos últimos se pueden originar de los 4 arcos branquiales, siendo los más frecuentes los quistes de segundo arco branquial con el $90 \%-95 \%$ de los casos, seguido por los de primer arco (5\%$8 \%)$ y finalmente $3^{\circ}$ y $4^{\circ} \operatorname{arco}(2 \%)^{2}$.

Durante el desarrollo embrionario de los arcos branquiales puede existir una obliteración incompleta de éstos expresándose posteriormente en malformaciones como quistes, senos o fístulas de arco branquial ${ }^{3}$. Las malformaciones del segundo arco branquial pueden ubicarse desde la amígdala palatina hasta el borde anterior del músculo esternocleidomastoide ${ }^{3}$, siendo su ubicación parafaríngea muy rara.

En el siguiente trabajo presentamos el caso clínico de un recién nacido con un quiste de segundo arco branquial de ubicación parafaríngea diagnosticado durante el periodo neonatal.

\section{CASO CLÍNICO}

Recién nacido (RN) de $40^{+1}$ semanas. Hijo de madre con antecedente de diabetes gestacional en tratamiento con metformina y embarazo controlado. Durante el $3^{\circ}$ trimestre de embarazo se pesquisa polihidroamnios leve. Se realiza cesárea de urgencia por desaceleraciones con APGAR 8-9 al nacer. Evoluciona con síndrome de distrés respiratorio transitorio respondiendo favorablemente. Sin embargo, a las $48 \mathrm{hrs}$ de vida presenta estridor inspiratorio intermitente evolucionando hacia el tercer día con incapacidad para alimentarse por boca. Al examen físico se observa en orofaringe un aumento de volumen que protruye de forma importante el paladar blando.

Es evaluado por otorrinolaringología encontrando un RN en buenas condiciones generales, alimentándose por sonda nasoenteral, sin requerimientos de oxígeno y sin estridor. Al examen físico destacaba abombamiento del paladar blando por lesión de consistencia quística con mucosa intacta que obstruía casi totalmente la orofaringe (Figura 1).

Se realiza una nasofibroscopía encontrando lesión voluminosa que ocupa completamente la rinofaringe y se proyecta a orofaringe, sin lograr identificar el origen de la lesión. Se indica protección de vía aérea con cánula orofaríngea y se solicita estudio de imágenes con TC y RM de cabeza y cuello. El estudio de imágenes con TC mostró una lesión quística voluminosa centrada en el espacio parafaríngeo derecho que se extiende medialmente obliterando en forma importante

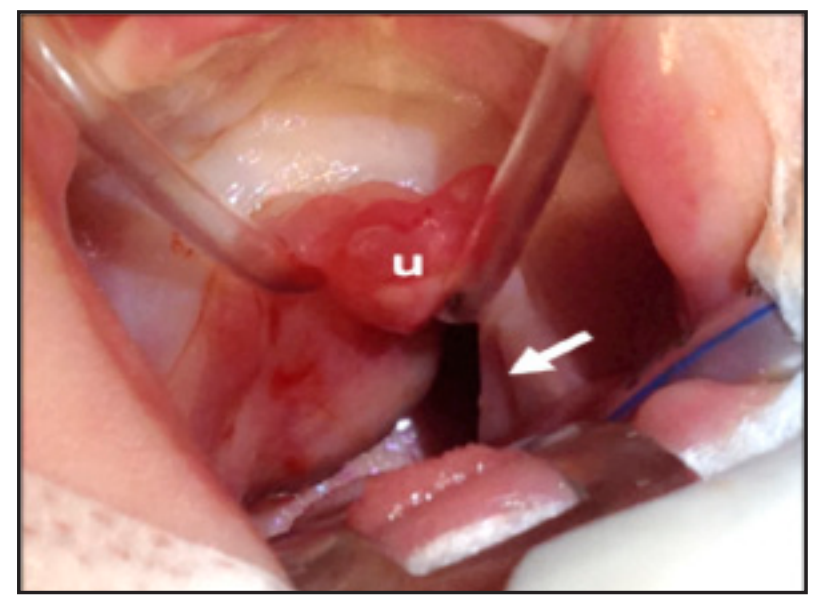

Figura 1. Examen físico orofaringe. Al elevar la úvula (u) se observa ocupación casi total de la orofaringe por lesión de aspecto quístico (flecha) y abombamiento de paladar blando. 


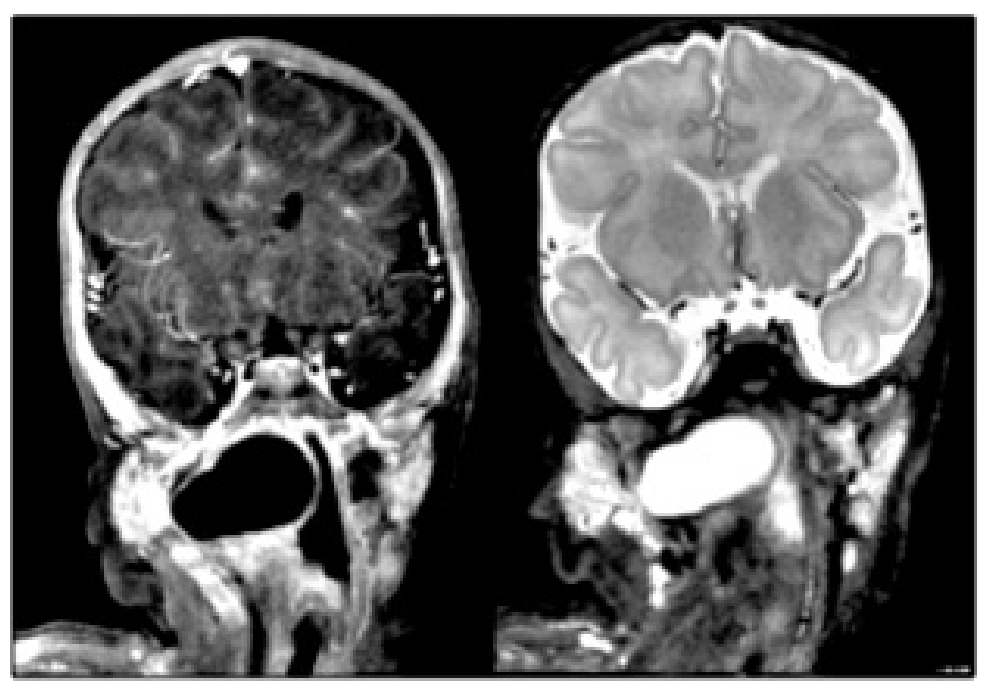

Figura 2. Cortes coronales de resonancia magnética. Se observa lesión quística del espacio parafaríngeo derecho hipointensa en T1 con gadolinio e hiperintensa en T2.

nasofaringe y orofaringe, cuyas dimensiones eran de $20 \times 35 \times 25 \mathrm{~mm}$, con captación parcial del medio de contraste en su periferia. La RM mostró una lesión hipointensa en T1 e hiperintensa en T2, de paredes discretamente engrosadas con sutil impregnación de contraste y sin alteración de la grasa circundante, cuyo componente lateral se extendía entre mandíbula y parótida y desplazaba la arteria carótida externa hacia anterolateral, sugiriendo como posible diagnóstico un quiste de segundo arco branquial (Figura 2).
Por vía transoral se realiza la exéresis del quiste mediante disección roma extracapsular. Se aspira su contenido con aguja fina obteniendo un líquido de aspecto seromucoso y se envía a estudio citológico que no mostró hallazgos específicos. Además, se envía una muestra de la pared quística a biopsia rápida que resulta sugerente de quiste branquial (Figura 3). Paciente evoluciona estable logrando la extubación a las 48 hrs posoperatorias. Al décimo día se inicia alimentación vía oral sin dificultad y el resultado de la biopsia diferida

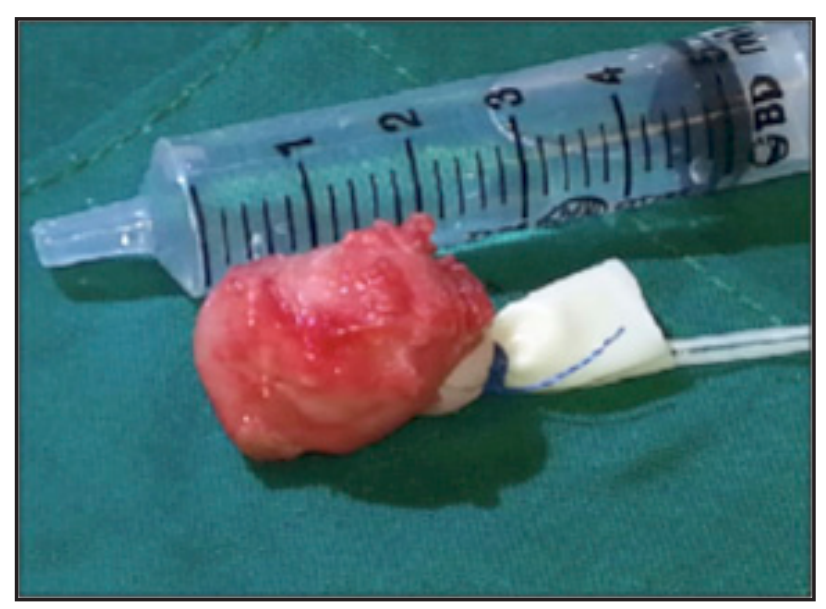

Figura 3. Cápsula quística posexéresis. 
confirma el diagnóstico de quiste branquial. Luego de un año de seguimiento no ha existido recidiva de la lesión.

\section{DISCUSIÓN}

Dentro de los quistes cervicales congénitos los quistes branquiales son los segundos en frecuencia luego del quiste tirogloso, representando el $24 \%$ de los casos ${ }^{1}$. Se pueden originar de los 4 arcos branquiales, siendo los más frecuentes los quistes de segundo arco branquial con el 90\%-95\% de los casos, seguido por los de primer arco (5\%-8\%) y finalmente $3^{\circ}$ y $4^{\circ}$ arco $(2 \%)^{2}$.

Durante el desarrollo embrionario de los arcos branquiales puede existir una obliteración incompleta de éstos, expresándose posteriormente en malformaciones congénitas como quistes, senos o fístulas de arco branquial ${ }^{3}$. Las malformaciones del segundo arco branquial pueden ubicarse desde la amígdala palatina hasta el borde anterior del músculo esternocleidomastoideo ${ }^{3}$, siendo su ubicación parafaríngea muy rara. Según Bailey, los quistes de segundo arco branquial se pueden clasificar en 4 tipos dependiendo de su localización y relaciones con estructuras adyacentes. Los quistes de tipo I son los más superficiales situados justo bajo la aponeurosis cervical superficial, por delante del borde anterior del músculo esternocleidomastoideo. Los quistes de tipo II están situados bajo la aponeurosis cervical media, por delante y lateral a los grandes vasos a los que puede adherirse, siendo el más frecuente de todos. Los quistes de tipo III se extienden hacia la faringe, entre la carótida interna y externa. A veces se prolongan hacia la base del cráneo, y los quiste de tipo IV son excepcionales y se sitúan entre la pared faríngea medialmente y el eje vascular por su parte lateral ${ }^{4}$. Nuestro caso corresponde a un quiste de tipo IV.

Respecto a su presentación clínica, se observan en un amplio rango de edad (entre los 10 a 40 años), siendo más frecuentes en hombres que en mujeres $(60 \% \text { vs } 40 \%)^{5}$. Generalmente se presentan como una masa cervical lateral recurrente que puede aparecer desde la fosa tonsilar hasta la zona supraclavicular. Si bien están presentes desde el nacimiento, su debut y diagnóstico ocurre en niños mayores 0 adultos ya que constituyen masas de crecimiento lento cuya primera manifestación clínica puede ser un aumento de volumen relativamente brusco por infección de la vía aérea superior².

El caso presentado resulta interesante por dos cosas: su ubicación parafaríngea y por la edad de presentación extremadamente temprana $\left(2^{\circ}\right.$ día de vida). Hasta la actualidad se han reportado menos de 50 casos de quistes de segundo arco branquial en el espacio parafaringe $0^{5-7}$. La edad de presentación es variable, desde los 2 hasta los 69 años, pero ningún caso ha sido diagnosticado en el periodo neonatal. En Chile existe un caso reportado de quiste de segundo arco branquial de tipo IV en un paciente de 7 años ${ }^{8}$. Otras lesiones del espacio parafaríngeo en niños han sido reportadas a nivel nacional, como un coristoma y un rabdomiosarcoma embrionario 9 .

El estudio imagenológico se realiza con TC y RM de cuello que son complementarios. En la TC, los quistes de segundo arco branquial por lo general se presentan sin realce de su pared, a no ser que estén infectados. Existe un signo característico de quiste de segundo arco branquial que corresponde al signo de Notch que es una proyección focal del quiste entre la bifurcación de la carótida común ${ }^{2,10}$. En la RM es característico encontrar una lesión quística hipointensa en la secuencia T1 e hiperintensa en la secuencia T2.

Histológicamente, estas lesiones pueden estar revestidas por epitelio escamoso estratificado no queratinizado combinado con un epitelio columnar ciliado de tipo respiratorio. Se puede encontrar abundante tejido linfoide con centros germinales o infiltrado inflamatorio linfocítico agudo, glándulas salivales y si es un proceso más crónico cristales de colesterol ${ }^{3}$.

Respecto al tratamiento de los quistes del espacio parafaríngeo se han descrito distintas técnicas con distintos abordajes, desde la aspiración con aguja fina con 0 sin escleroterapia hasta la extirpación completa de la lesión ${ }^{6}$. Sin embargo, en todos los casos de manejo más conservador hubo recurrencia del quiste teniendo que recurrir a la cirugía para la extirpación completa de la lesión. Actualmente no existe discusión en que el estándar de tratamiento es la extirpación total del quiste. Se pueden utilizar distintas vías de abordaje al espacio parafaríngeo. La vía transoral es de elección en quistes que no son palpables en el cuello mientras que la vía transcervical se utiliza en lesiones inferiores con componente palpable en cuello porque 
permite la mayor exposición para una resección completa de la lesión. La vía transcervical transparotídea se utiliza en lesiones superiores en las que se quiere preservar el facial ${ }^{6,11}$.

Los pacientes deben ser controlados por un buen tiempo por el riesgo de recurrencia de la patología, que es bastante poco frecuente si se realiza una correcta extirpación (3\%). Sin embargo, si previo a la cirugía han presentado infecciones recurrentes, el riesgo de recidiva es mayor $(20 \%)^{7}$.

\section{BIBLIOGRAFÍA}

1. Cejas C, Benvenuti P, De Barrio G, Parlato M, Remis Federico. Masas Cervicales. Rev Argent Radiol 2007; 71(1): 45-54.

2. García C, O’Brien A, Villanueva E, Otero J, Parra R. Anomalías Congénitas del Aparato Branquial: Estudio de Imágenes. Rev Chil Radiol 2007; 13(3): 147-53.

3. La Riviere CA, Waldhausen JH. Congenital cervical cysts, sinuses, and fistulae in pediatric surgery. The Surgical Clinics of North America 2012; 92(3): 583-97.

4. Beauvillain C, Bordure P, Ferri-Launay ML. Chirurgie de l'espace parapharyngé. Encyclopédie Médical Chirurgie, Editions Scientifiques et Médicales Elsevier SAS, Paris 2001. E- 46-490.

5. Ghosh S, Tarun KR, Datta S, Banka A. Parapharyngeal second branchial cyst: a case report. Indian Journal of Otolaryngology and Head and Neck Surgery 2006; 58(3): 283-4.

6. Bilgen C, Ögüt F, ÇeltikLioglu F. A new case of a

\section{CONCLUSIÓN}

Los quistes de segundo arco branquial del espacio parafaríngeo son muy raros, existiendo pocos casos reportados. Sin embargo, lo que hace que el caso presentado sea más raro aún es la edad de presentación. Independientemente de esto el manejo sigue siendo la extirpación quirúrgica completa y el seguimiento de los pacientes por el riesgo de recurrencia. branchial cyst of the parapharyngeal space. Ear, nose and throat Journal 2001; 80(6): 384-9.

7. Yong J, Yoon S, Ho Lee Ch, Ho Yoon P, Sung K. Parapharyngeal branchial cleft cyst extending to the skull base: A lateral transzygomatictranstemporal approach to the parapharyngeal space. Neurosurg Rev 2004; 28: 73-6.

8. Veloz M, Pacheco A. Presentación de quiste de segundo arco branquial como masa orofaríngea: Reporte de un caso. Rev Otorrinolaringol Cir Cabeza Cuello 2015; 75(2): 157-60.

9. Cabezas L, Bertín H, Salinas F, Sanhueza P. Tumores parafaríngeos en niños: Descripción de dos casos clínicos. Rev Otorrinolaringol Cir Cabeza Cuello 2000; 60; 35-8.

10. Friedman E, John S. Imaging of pediatric neck masses. Radiologic Clinics of North America 2011; 49(4): 617-32.

11. Ohta N, Fukase S, Suzuki Y, Ishida A, Aovagi M. Treatments of various otolaryngological cystic diseases by $0 \mathrm{~K}-4321$ : its indications and limitations. The Laryngoscope 2010; 120(11): 2193-6. 